\title{
Aggressive angiomyxoma of pelvic parts exhibits oestrogen and progesterone receptor positivity
}

\author{
W G McCluggage, A Patterson, P Maxwell
}

\begin{abstract}
Aims-Aggressive angiomyxoma of pelvic parts is a distinctive soft tissue tumour that chiefly involves the vulvar and perineal region of female patients. Several previous reports have demonstrated oestrogen receptor (ER) and/or progesterone receptor (PR) positivity in this neoplasm. The aim of this study was to confirm whether ER and/or PR positivity is present in aggressive angiomyxoma. We also wished to ascertain whether positivity may be found in the stromal cells of normal vulval skin and in other lesions at this site that can cause diagnostic confusion with aggressive angiomyxoma.

Methods-Five aggressive angiomyxomas in female patients and one involving male pelvic soft parts were stained immunohistochemically with antibodies against ER and PR. Other samples studied were normal vulval skin $(n=7)$, fibroepithelial polyps of vulva $(\mathbf{n}=7)$, vulval smooth muscle neoplasms $(n=5)$, vulval nerve sheath tumours $(n=2)$, vaginal angiomyofibroblastoma $(n=1)$, and pelvic myxoma $(n=1)$. Nuclear staining was classified as negative, weak, moderate, or strong and the proportion of positively staining cells was categorised as $0,<10 \%$, $10-50 \%$, or $>50 \%$.
\end{abstract}

Results-All five cases of aggressive angiomyxoma in female patients were positive for ER (two with weak intensity involving $<10 \%$ of cells and three with moderate intensity involving $10-50 \%$ of cells) and four of five cases were strongly positive for PR in $>50 \%$ of cells. The other case was negative for PR. There was no staining with antibodies to $\mathrm{ER}$ or PR in the single male patient with aggressive angiomyxoma. Other samples exhibiting positivity of the stromal cells for either ER or PR were normal vulval skin (five of seven, ER; two of seven, PR), fibroepithelial polyps (four of seven, ER; five of seven, PR), smooth muscle neoplasms (three of five, ER; four of five, PR), nerve sheath tumours (one of two, ER; one of two, PR), angiomyofibroblastoma (one of one, ER; one of one, PR), and pelvic myxoma (one of one, PR).

Conclusions-All cases of aggressive angiomyxoma of pelvic soft parts in female patients exhibited positivity for ER and/or PR. Because of its propensity to occur in female patients during the reproductive years, it is possible that aggressive angiomyxoma is a hormonally responsive neoplasm. However, dermal fibroblasts in normal vulval skin and stromal cells in a variety of vulval lesions can also be positive. ER or PR immunoreactivity cannot be used to distinguish aggressive angiomyxoma and its histological mimics. (F Clin Pathol 2000;53:603-605)

Keywords: aggressive angiomyxoma; vulva; oestrogen receptor; progesterone receptor; immunohistochemistry

Aggressive angiomyxoma of pelvic parts, which was described by Steeper and Rosai in 1983, is a neoplasm that chiefly involves the vulval and perineal region of young women. ${ }^{1}$ Despite its benign histological appearance, and although it does not metastasise, the neoplasm exhibits a pronounced tendency for local, often multiple recurrences. ${ }^{12}$ Because of this, aggressive angiomyxoma must be distinguished from a variety of benign and malignant lesions that can be close histological mimics. It has been suggested that aggressive angiomyxoma might be hormone dependent and rapid growth has been observed during pregnancy. ${ }^{3}$ In addition, several reports have demonstrated oestrogen receptor (ER) and/or progesterone receptor (PR) positivity within this neoplasm, either by immunohistochemistry or by direct assay. ${ }^{3-7}$ The aim of our study was to investigate the ER and PR status of six cases of aggressive angiomyxoma, including one in a male patient. We wished to determine whether this would be of value in the distinction between aggressive angiomyxoma and a variety of lesions that can mimic it. To this end, samples of normal vulval skin and of a variety of vulval lesions were also investigated.

Materials and methods

Specimens included in our study were retrieved from the files of the department of pathology, Royal Group of Hospitals Trust, Belfast and are shown in table 1 . Two of the vulval fibroepithelial polyps had a myxoid stroma. Specimens had been fixed in formalin and routinely processed in paraffin wax. The pelvic myxoma occurred in a patient with Carney's syndrome.

Paraffin wax embedded sections were cut at $4 \mu \mathrm{m}$ on to coated slides (aminopropyltriethoxysilane; Sigma, Poole, Dorset, UK) and dried at $37^{\circ} \mathrm{C}$ overnight. After dewaxing and blocking of endogenous peroxidase activity in 3\% alcoholic hydrogen peroxide, all sections were incubated in $0.01 \mathrm{M}$ citrate buffer $(\mathrm{pH} 6.0)$ in a microwave oven (Whirlpool, $850 \mathrm{~W}$ ) at full power for 20 minutes and allowed to cool for a further 20 minutes. Primary antibodies (ER clone 1D5 and PR clone 1A6; Dako, Ely, UK) 
Table 1 Immunohistochemical results of staining for oestrogen receptors (ER) and progesterone receptors (PR)

\begin{tabular}{|c|c|c|c|c|}
\hline \multirow[b]{2}{*}{ Study cases } & \multicolumn{2}{|l|}{ Intensity of staining } & \multicolumn{2}{|c|}{ Proportion of positive staining cells } \\
\hline & $E R$ & $P R$ & $E R$ & $P R$ \\
\hline AA in female patients $(n=5)$ & $2 \mathrm{~W}, 3 \mathrm{M}$ & $1 \mathrm{~N}, 4 \mathrm{~S}$ & $2+, 3++$ & $10,4+++$ \\
\hline AA in a male patient $(n=1)$ & $1 \mathrm{~N}$ & $1 \mathrm{~N}$ & 10 & 10 \\
\hline Normal vulval skin $(n=7)$ & $2 \mathrm{~N}, 1 \mathrm{~W}, 2 \mathrm{M}, 2 \mathrm{~S}$ & $5 \mathrm{~N}, 1 \mathrm{M}, 1 \mathrm{~S}$ & $20,1+, 4++$ & $50,2+++$ \\
\hline Fibroepithelial polyp of vulva $(n=7)$ & $3 \mathrm{~N}, 2 \mathrm{~W}, 2 \mathrm{M}$ & $2 \mathrm{~N}, 1 \mathrm{~W}, 3 \mathrm{M}, 1 \mathrm{~S}$ & $30,3++, 1+++$ & $20,3++, 2+++$ \\
\hline Vulval smooth muscle neoplasm $(n=5)$ & $2 \mathrm{~N}, 2 \mathrm{~W}, 1 \mathrm{M}$ & $1 \mathrm{~N}, 2 \mathrm{M}, 2 \mathrm{~S}$ & $20,1+, 1++, 1+++$ & $10,4+++$ \\
\hline Vulval nerve sheath tumour $(\mathrm{n}=2)$ & $1 \mathrm{~N}, 1 \mathrm{~S}$ & $1 \mathrm{~N}, 1 \mathrm{M}$ & $10,1+++$ & $10,1++$ \\
\hline Vaginal angiomyofibroblastoma $(\mathrm{n}=1)$ & $1 \mathrm{~S}$ & $1 \mathrm{~S}$ & $1+++$ & $1+++$ \\
\hline Pelvic myxoma $(\mathrm{n}=1)$ & $1 \mathrm{~N}$ & $1 \mathrm{~W}$ & 10 & $1++$ \\
\hline
\end{tabular}

AA, aggressive angiomyxoma; $M$, moderate; $N$, negative; $S$, strong; W, weak; o, no cells;,$+<10 \%$ cells;,$++ 10-50 \%$ cells,,$+++>$ $50 \%$ cells positive.

were diluted $1 / 50(5 \mu \mathrm{g} / \mathrm{ml}$ and $0.3 \mu \mathrm{g} / \mathrm{ml}$, respectively) in Tris buffered saline (Sigma) and the sections incubated overnight at $4^{\circ} \mathrm{C}$ and for one hour at $37^{\circ} \mathrm{C}$, respectively.

Immunolocalisation was performed using a peroxidase streptavidin-biotin complex (Dako) method. Diaminobenzidine (Dako) acted as the chromogen and the sections were counterstained in Harris's haematoxylin.

Positive controls were run with each batch. These consisted of a composite block containing varying degrees of $E R$ and $P R$ expression. Negative controls were run on each test case and consisted of omission of primary antibody or replacement of primary antibody with respective immunoglobulin isotype controls at concentrations comparable with test cases.

Nuclear staining was classified as negative, weak, moderate, or strong. The proportion of positive staining cells was classified as $0,+$ ( $<10 \%$ of cells), $++(10-50 \%$ of cells $)$, or +++ ( $>50 \%$ of cells).

\section{Results}

Table 1 shows the results of the immunohistochemical staining with antibodies to ER and

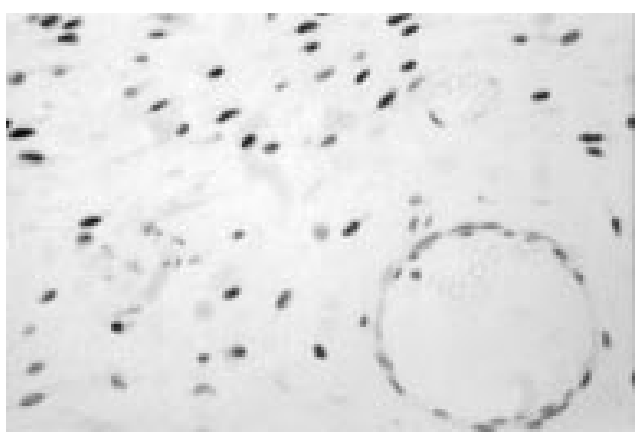

Figure 1 Positive staining of stromal cells for the oestrogen receptor in a female patient with aggressive angiomyxoma.

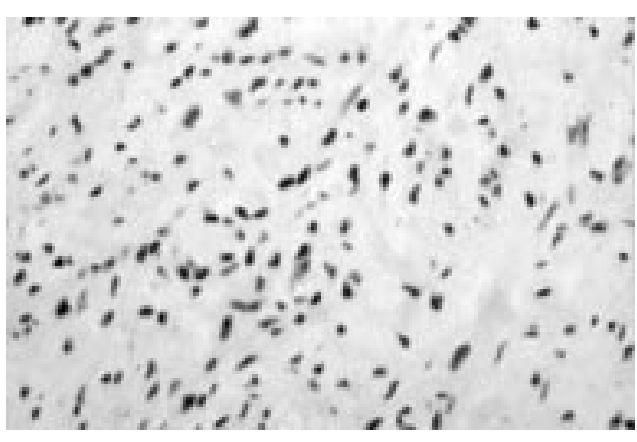

Figure 2 Positive staining of stromal cells for the progesterone receptor in a female patient with aggressive angiomyxoma.

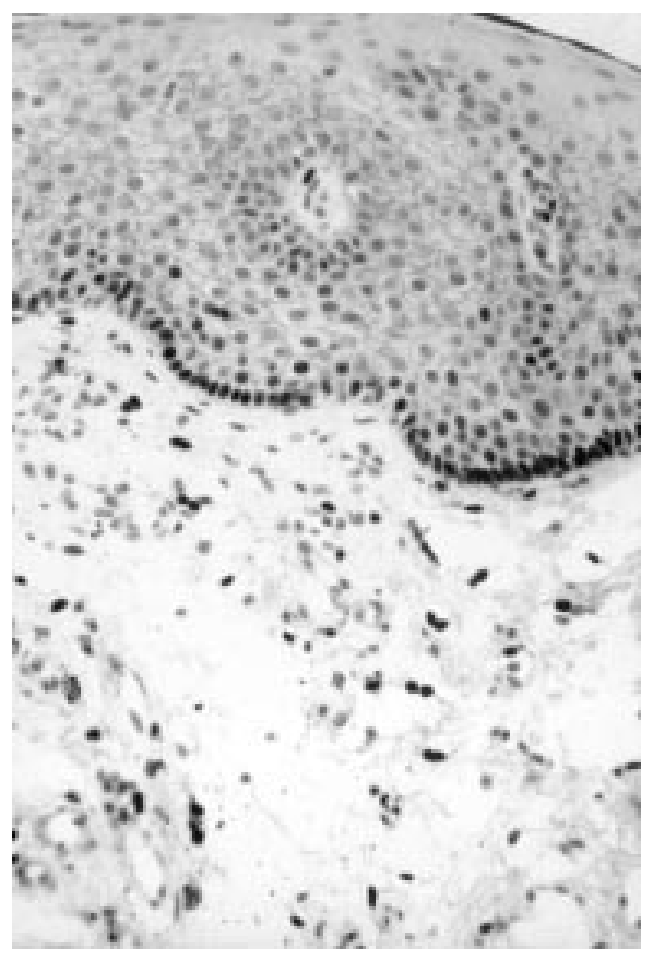

Figure 3 Positive nuclear staining for the oestrogen receptor of basal layers of squamous epithelium of normal vulval skin. There is also positive staining of some dermal fibroblasts.

PR. There was weak to moderate positivity for ER in all female patients with aggressive angiomyxoma. In the two cases where staining was weak, $<10 \%$ of cells were positive, and in the three cases where staining was moderate, $10-50 \%$ of cells stained positively (fig 1 ). There was strong staining of $>50 \%$ of cells for $\mathrm{PR}$ in four cases (fig 2) and the other case was entirely negative. There was no staining with antibodies to ER or PR in the male patient with aggressive angiomyxoma. Both vulval fibroepithelial polyps with a myxoid stroma exhibited positivity for ER and PR.

In all instances, there was staining of positive control material but no staining of negative controls. In some cases, there was positive nuclear staining of the basal layers of vulval surface squamous epithelium for ER (fig 3). There was no nuclear staining of the squamous epithelium for PR.

\section{Discussion}

Aggressive angiomyxoma is a locally infiltrative, but non-metastasising, lesion chiefly involving the vulvar and perineal region of 
women and girls during the reproductive years. Histologically, the neoplasm is composed of myofibroblastic cells and prominent blood vessels within a myxoid stroma. Hormone dependency has been suggested based on a single case report of a lesion that grew rapidly during pregnancy. ${ }^{3}$ In addition, other reports have demonstrated ER and/or PR positivity within aggressive angiomyxoma. ${ }^{3-7}$ In our study, all five females patients showed positivity for ER, staining being weak or moderate in intensity. Four or five cases were strongly positive for PR throughout most of the tumour. The immunohistochemistry suggests that, in at least some cases, aggressive angiomyxoma might be a hormone responsive neoplasm. Recently, aggressive angiomyxoma has been described in male pelvic parts, ${ }^{8-10}$ but there was no staining with antibodies to either ER or PR in the single male patient investigated. It is of interest that positivity with androgen receptors has been demonstrated in aggressive angiomyxoma in a male patient, ${ }^{11}$ suggesting that in men the neoplasm might also be hormone dependent.

The observed positivity in aggressive angiomyxoma for ER and PR raises the possibility that hormonal manipulation might have a role in the management of this lesion. Aggressive angiomyxoma shows a similar propensity for infiltrative growth and local recurrence as do fibromatosis and desmoid tumours. Abdominal fibromatosis commonly arises in women during the reproductive years and rapid growth has been observed during pregnancy. ER and PR positivity has been observed in fibromatosis and there have been reports of a dramatic clinical response to the antioestrogen, tamoxifen. ${ }^{12} 13$ It could be hypothesised that hormonal treatment with tamoxifen or with gonadotropin releasing hormone agonists, such as goserelin, might be of value in the management of aggressive angiomyxoma, especially in recurrent cases that are not amenable to surgical resection.

Diagnostic confusion can arise between aggressive angiomyxoma and a wide range of other myxoid lesions involving the vulvar region. This includes benign harmless lesions as well as malignant tumours with metastatic potential. It is not the purpose of our report to reiterate the differential diagnosis, which has been dealt with adequately in previous studies. ${ }^{14}{ }^{15}$ However, the differential diagnosis might include fibroepithelial polyps with a myxoid stroma, myxoid smooth muscle and nerve sheath tumours, angiomyofibroblastoma, and myxoma. Small numbers of these lesions were included in our study and these showed variable reactivity with ER and PR, suggesting that among vulval mesenchymal lesions positivity is not unique to aggressive angiomyxoma. Indeed, positivity with ER and/or PR was present in dermal fibroblasts in most samples of normal vulval skin. A previous study investigating the ER status of the vulva and vagina showed positivity within epithelial and stromal cells. ${ }^{16}$

In conclusion, ER and/or PR positivity is present in aggressive angiomyxoma of pelvic soft parts in women. This suggests that aggressive angiomyxoma might be a hormone responsive neoplasm. However, positive staining can be present in a variety of other mesenchymal lesions involving this region, and immunoreactivity with ER and/or PR is of no value in distinguishing aggressive angiomyxoma from other lesions that can mimic it. ER and PR can also be demonstrated in normal dermal fibroblasts in the vulva and positivity within vulval mesenchymal lesions might simply be a reflection of this.

We thank Dr Marie Madden (Altnagelvin Area Hospital, Londonderry, Northern Ireland) for providing us with material for this study.

1 Steeper TA, Rosai J. Aggressive angiomyxoma of the female pelvis and perineum: report of nine cases of a distinctive type of gynecologic soft tissue neoplasm. Am f Surg Pathol type of gynecologic
$1983 ; 7: 463-75$.

2 Begin LR, Clement PB, Kirk ME, et al. Aggressive angiomyxoma of pelvic soft parts: a clinicopathologic study of nine cases. Hum Pathol 1985;16:621-8.

3 Fetsch FJ, Laskin WB, Lefkowitz M, et al. Aggressive angiomyxoma. A clinicopathologic study of 29 female patients. Cancer 1996;78:79-90

4 Htwe M, Deppisch LM, Saint-Julien JS. Hormonedependent aggressive angiomyxoma of the vulva. Obstet Gynecol 1995;86:697-9.

5 Havel G, Burian P, Kohrtz M, et al. Aggressive angiomyxoma of the vulva: an unusual, deceptive and recurrence-prone tumour with evidence of estrogen receptor expression. APMIS 1994;102:236-40.

6 Rotmensch EJ, Kasznica J, Hamid MA. Immunohistochemical analysis of hormone receptors and proliferating cell nuclear antigen in aggressive angiomyxoma of the vulva. Int 7 Gynaecol Obstet 1993;41:171-9.

7 Sutton GP, Rogers RE, Roth LM, et al. Aggressive angiomyxoma first diagnosed as levator hernia. Am $\mathcal{F}$ Obstet angiomyxoma first diagn

8 Tsang WYW, Chan JKC, Lee KC, et al. Aggressive angiomyxoma. A report of four cases occurring in men. Am 7 Surg Pathol 1992;16:1059-65.

9 Clatch RJ, Drake WK, Gonzalez JG. Aggressive angiomyxoma in men. A report of two cases associated with inguinal hernias. Arch Pathol Lab Med 1993;117:911-13.

10 Iezzoni JG, Fechner RE, Wong LE, et al. Aggressive angiomyxoma in males. A report of four cases. Am 7 Clin Pathol 1995; 104:391-6.

11 Silverman JS, Albukerk J, Tamsen A. Comparison of angiomyofibroblastoma and aggressive angiomyxoma in both sexes: four cases composed of bimodel CD 34 and factor XIII a positive dendritic cell subsets. Pathol Res Pract 1997;93:673-82

12 Pierce VE, Rives DA, Sisley JF, et al. Estradiol and progesterone receptors in a case of fibromatosis. Arch progesterone receptors in a cas
Pathol Lab Med 1987;111:870-2.

13 Kintzbrunner B, Ritter S, Domingo J, et al. Remission of rapidly growing desmoid tumours after tamoxifen therapy. Cancer 1983;52:2201-4.

14 Granter SR, Nucci MR, Fletcher CDM. Aggressive angiomyxoma: reappraisal of its relationship to angiomyofibroblastoma in a series of 16 cases. Histopathology 1997;30: 3-10.

15 Nemoto T, Shinoda M, Komatsuzaki K, et al. Myxoid leiomyoma of the vulva mimicking aggressive angiomyxoma. Pathol Int 1994;44:454-9.

16 MacLean AB, Nicol LA, Hodgins MB. Immunohistochemical localization of estrogen receptors in the vulva and vagina. $\mathcal{F}$ Reprod Med 1990;35:1015-16. 